\title{
ЛИНГВОКУЛЬТУРНЫЙ КОНЦЕПТ КАК УСЛОВНАЯ МЕНТАЛЬНАЯ ЕДИНИЦА
}

\section{LINGUISTIC AND CULTURAL CONCEPT AS A CONDITIONAL MENTAL UNIT}

O. Litvyak

E. Smirnova

Summary: The article presents a research model for constructing a linguocultural concept. The main elements of the concept are considered. In addition, it is revealed that the concept is of value for the concept of the features of the worldview of a language group, the approaches and classifications of the concept as a tool for the formation and interpretation of the language mentality are described. A concept is a conditional mental unit where you can consider the idea of a part of the world or the world as a whole, or a complex fragment that has different features, which are implemented in different language ways and means. Considering the structure of the concept, it can be argued that the national language is not only a means of communication, but also a kind of substitute for culture. Considering the concepts of any nation, you can find the relationship between language and culture. Each concept can be deciphered in different ways, based on context and cultural experience. According to the philosophical definition, where this term originated, a «concept» is a kind of explanation, a mental image, a thought, a concept a conceptual feature can be objectified in different forms of combinations of linguistic units that are representatives of the concept. Cultural concepts are the value components of culture, which are expressed by abstract names.

Keywords: linguoculturology, national picture of the world, cognitive linguistics, mentality, concept, language mentality, methodology, conceptual analysis.
Литвяк Олеся Валерьевна

К.филол.н., дочент, Крымский инженерно-педагогический университет имени Февзи Якубова, г. Симферополь

ole.litviak@yandex.ru

Смирнова Елизавета Ярославовна Крымский инженерно-педагогический университет имени Февзи Якубова, г. Симферополь liza-meshh@yandex.ru

Аннотация: В статье представлена исследовательская модель построения лингвокультурного концепта. Рассматриваются главные элементы концепта. Кроме этого, выявляется, что концепт представляет ценность для понятия особенностей мировидения языкового коллектива, описываются подходы и классификации концепта как инструмента формирования и интерпретации языкового менталитета. Концепт - это условная ментальная единица, где можно рассмотреть представление о части мира или о мире в целом, или сложном фрагменте, имеющими разные признаки, которые реализуются разными языковыми способами и средствами. Рассматривая структуру концепта, можно утверждать, что национальный язык является не только средством общения, но и является своего рода заместителем культуры. Рассматривая концепты любого народа, можно найти взаимосвязь языка и культуры. Каждый концепт может быть расшифрован различными способами, исходя из контекста и культурного опыта. Согласно философскому определению, где этот термин и зародился, «концепт» - это своего рода объяснение, умственный образ, мысль, понятие концептуальный признак может объективироваться в разных формах сочетаний языковых единиц, являющихся репрезентантами концепта. Культурные понятия - это ценностные составляющие культуры, которые выражаются абстрактными названиями.

Ключевые слова: лингвокультурология, национальная картина мира, когнитивная лингвистика, ментальность, концепт, языковой менталитет, методология, концептуальный анализ.

вистики. К таким понятиям относится «концепт», который является определяющим понятием и инструментом оперирования в когнитивной лингвистике. Как пишет Скребцова: «Исследования отраженной в русском языке наивной картины мира способствовали формированию особого направления, связанного с анализом так называемых «концептов» [16].

Согласно философскому определению, где этот термин и зародился, «концепт» - это своего рода объяснение, умственный образ, мысль, понятие [13].

Прежде всего, поиск того или иного определения следует искать в словаре. В словаре когнитивных терминов Е.С. Кубряковой концепт определяется как «единица ментальных и психических ресурсов» [8]. Следует отметить, что концепт, по данному источнику, определяется 
«не как единое целое, а с разных позиций: как единица сознания, языка, и, наконец, «единица языка мозга». Причем, самому понятию «единица мозга» не дается четкого определения. Данный термин был предложен Ю.Н. Карауловым, который определяет «язык мозга» как «ничейную зону» между языком и мышлением.

Каждый язык отражает действительность определенным способом, следовательно, языки отличаются своими языковыми картинами мира. Т.Г. Скребцова утверждает, что в когнитивной лингвистике можно увидеть, как достоинства, так и недостатки, в связи с неоднородностью ее направления, отсутствием четкой платформы и исследовательской программы, а также можно увидеть достоинства, и лингвист любого направления может найти то, что подходит ему. Прежде всего, это междисциплинарные аспекты исследований. Что касается лингвиста, то он может заинтересоваться развитием языка [16].

Изучением концептов занималось большое количество отечественных и зарубежных исследователей. Вопросами, которые сопоставляются со структурами концептов, занимаются такие отечественные и зарубежные ученые, как С.Г. Воркачев, В.И. Карасик, И.А. Стернин, Ю.С. Степанов и многие другие. Следует проанализировать представление о концепте, отраженное в работах различных исследователей. Д.С. Лихачев использовал термин «концепт» для обозначения «обобщенной мыслительной единицы, интерпретирующей явления действительности в зависимости от образования, личного, профессионального и социального опыта носителя языка».

Исследованием концепта плодотворно занимались и занимаются Р.Д. Арутюнова, А. Вежбицкая, Е.С. Кубрякова, В.А. Маслова и др.

По мнению Н.Д. Красавского, концепт является когнитивной структурой, находящейся в лингвокультурном контексте и связанным с дискурсом [7].

В.А. Маслова считает, что отсутствие единого определения понятия «концепт» связано с тем, что у концепта сложная многомерная структура, включающая помимо понятийной основы социо-психо-культурную часть, которая не столько мыслится носителем языка, сколько переживается им, она включает ассоциации, эмоции, оценки, национальные образы и коннотации, присущие данной культуре». По ее мнению, концепты являются своего рода посредниками между словами и действительностью, и значение слова не может быть сведено к образующим его концептам. Концепт определяется как «семантическое образование, отмеченное лингвокультурной спецификой и характеризующее носителей определенной этнокультуры, которое окружено эмоциональным, экспрессивным, оценочным ореолом».
Среди признаков концепта, которые выделяет В.А. Маслова можно отметить следующие: концепт представляет собой минимальную единицу человеческого опыта, которая вербализуется при помощи слова; концепт представляется основной единицей обработки, хранения и передачи информации; концепт имеет конкретные функции; концепт предстает как основная ячейка культуры. Вся познавательная деятельность человека, по мнению В.А. Масловой, умение, помогающее ориентироваться в мире. В этой деятельности есть необходимость отождествлять и различать объекты [12].

B.А. Пищальникова утверждает, что концепт - это категория, которая объединяет все характеристики объекта: визуальные, тактильные, слуховые, вербальные и другие [14]. По мнению Ю.С. Степанова, концепт и понятие относятся к разным наукам. Понятие больше относится к философии, концепт же больше относится к лингвистике, психологии, логике, культуре и культурологии. Он утверждает, что можно говорить о культурологическом направлении в когнитивной лингвистике, поскольку концепт исследуется как элемент культуры на основе различных культур [19].

Культурные понятия - это ценностные составляющие культуры, которые выражаются абстрактными названиями. По мнению И.А. Степанова, концептуальные признаки - единица структурированного знания, представляющая собой совокупность элементов, которые классифицируются по различным критериям: по своей значимости, степени абстрактности, форме, функции и т.д. В связи с активной динамической ролью концепта в процессе мышления, эти признаки могут существовать в строго структурированной организации [19].

У каждого лингвиста своя интерпретация термина «концепт». З.Д. Попова, И.А. Стернин, считают, что концепт - это ненаблюдаемая категория, это только мыслительная категория. Образная сторона концепта заключается в воспринимаемых органами чувств характеристики предметов, явлений, отраженных в памяти. Они определяют концепт как «базовую единицу мыслительного кода человека, обладающую упорядоченной внутренней структурой, представляющую собой результат познавательной деятельности личности и общества и несущую комплексную, энциклопедическую информацию об отражаемом предмете и явлении, об интерпретации данной информации общественным сознанием и отношении общественного сознания к данному явлению или предмету» [15].

С этим определением нельзя не согласиться, так как концепт - есть отражение культуры в таком виде, в котором ее преподносит носитель этой самой культуры. 3.Д. Попова и И.А. Стернин считают, что «концепт кодируется в сознании индивидуальным чувственным образом, 
вступающим как чувственный компонент содержания концепта, и является базовой единицей универсального предметного кода человека». Проанализировав множество определений концепта, говорят о том, что концепт может формироваться в сознании человека из восприятия мира органами чувств, его предметной деятельности, мыслительных операций и так далее [15].

Структура концепта содержит признаки, функционально значимые для определенной культуры. Концепт - это представление о фрагменте мира» [13].

Н.Д. Арутюнова пишет о концепте как о философском понятии, которое является результатом взаимодействия нескольких факторов: фольклора, национальной традиции, религии, идеологии и так далее. Концепты образуют «своего рода культурный слой, посредничающий между человеком и миром». Согласно ей, концепты могут образовывать культурный слой, который может выступать в качестве посредника между человеком и миром. Концепт, в данном случае, может трактоваться как результат взаимодействия нескольких факторов: национальная традиция, фольклор, религия, идеология и так далее [1].

По определению С.Г. Воркачева концепт - «операционная единица мысли», «единица коллективного знания (отправляющая к высшим духовным сущностям), которая имеет языковое выражение и отмеченная этнокультурной спецификой» [5]. Если ментальное образование не имеет этнокультурной специфики, оно, по мнению ученого, к концептам не относится [3].

С точки зрения Н.А. Красавского, концепт рассматривается как когнитивная структура, погруженная в лингвокультурный контекст. Концепт напрямую связан с дискурсом. [7] Согласно мнению некоторых исследователей, концепт имеет словесное выражение, в противном случае нельзя говорить о наличии в культуре концепта.

Лингвокультурный концепт обладает рядом важнейших характеристик.

Г.Г. Слышкин выделяет следующие: комплексность бытования, ментальная природа, ценностность, условность и размытость, изменчивость, ограниченность сознанием носителя, трехкомпонентность, полиапеллируемость, многомерность, методологическая открытость и поликлассифицируемость, когнитивно-обобщающая направленность [17]. Рассмотрим далее каждую характеристику по отдельности.

Лингвокультурный концепт - это условная ментальная единица, направленная на комплексное изучение языка, сознания и культуры [19]. Концепт формируется и реализуется на стыке языка, культуры и сознания.
Ментальная природа. В сознании осуществляется взаимодействие языка и культуры, процесс восприятия, категоризации и коммуникативной репрезентации. Концепт участвует в каждом из этих процессов, а значит, находится в сознании и имеет ментальную природу.

Ценностность. Ценность является центром лингвокультурного концепта, так как он служит средством исследования культуры, а в основе культуры лежит ценностный принцип.

Условность и размытость. Ментальная деятельность человека не имеет четкой, логической структуры, а членится только в целях ее исследования. Таким образом, концепт, как и ментальность, не имеет четких границ и находится в состоянии некоей размытости.

Изменчивость. Концепт как часть культуры, имеет некоторый социальный характер, что означает, что концепт динамичен и подвергается постоянному влиянию явлений действительности. В ходе жизни языкового коллектива актуальность концептов может меняться. Концепт даже может менять оценочный знак с отрицательного на положительный или с положительного на отрицательный. Меняются также образная и понятийная (фактуальная) составляющие лингвокультурной категории.

Ограниченное сознание носителя. Понятие может существовать в индивидуальном и коллективном сознании, понятия индивидуума более богаты и разнообразны, поскольку они первичны. Это индивидуальные концепции, которые формируют коллективные, суммируя повторяющиеся явления и устраняя индивидуальный опыт.

Три компонента. В дополнение к вышеуказанному элементу стоимости в структуре концепции можно выделить фактические и переносные элементы. Фактический элемент концепции хранится в уме в словесной форме и поэтому может быть воспроизведен в речи; образный элемент выражен невербально и может быть описан только [17].

Полиапеллируемость. ««Вход в категорию» может быть не только одной конкретной единицей. Обращение к понятию представляется возможным с помощью единиц разных языковых уровней: морфем, словоформ, токенов, фразеологизмов, свободных фраз и предложений.

Многомерность. Традиционные единицы когнитивной науки (рамки, сценарии, сценарии и т. д.), имеющие структуру, более четкую, чем концепция, могут быть более удобными для моделирования лингвокультурной категории. Например, рамки и концептуальные метафоры часто используются для моделирования категорий и концептов [18]. 
Методологическая открытость и поликлассифицируемость. В рамках лингвистических и культурных исследований поощряется использование лингвистических и нелингвистических методов, поскольку эта научная отрасль является междисциплинарной. Лингвистические и культурные концепции могут быть классифицированы по различным признакам, например, по предмету, по среде, по типу дискурса, по типу трансляции.

Наиболее важной является характеристика трехкомпонентности, которая подробно описана В.И. Карасиком. Данная структурная модель концепта включает в себя фактуальный (понятийный), образный и ценностный элементы. Образный элемент отражает чувственное восприятие предмета, явления, события; он включает в себя внутренние формы языковых знаков. Понятийная сторона категории - это языковая репрезентация категории; она представляет собой повседневное знание или общую эрудицию. Ценностная составляющая сторона определяет важность той или иной лингвокультурной категории как для индивидуума, так и для коллектива [6]. Ценностный элемент является определяющим, так как именно он позволяет выделить концепт, в то время как понятийный и образный элементы являются способами осмысления действительности [6].

Основным методом для описания вышеперечисленных составляющих концепта является метод «концептуального анализа». Данная форма научного исследования находит свое применение в таких ведущих направлениях современной лингвистики, как «когнитивная лингвистика» и «лингвокультурология». Концептуальный анализ может осуществляться различными способами: изучение концептов, стоящих за конкретной лексикой, рассмотрение ключевых слов эпохи, а также определение структур знаний, стоящих за классами слов [9].

Концептуальный анализ имеет определенную методику исследования. В первую очередь, именно лексика является главным объектом анализа. Тем не менее, концептуальный анализ включает в себя исследование семантики имени концепта, его этимологии, синонимов, антонимов, сложных слов и ценностно-маркированных высказываний, объективирующих этот концепт, анализ текстов в разных типах дискурса, а также психолингвистический эксперимент, с помощью которого определяется ассоциативное поле концепта [10].
Описание лексических единиц, с помощью которых объективируется концепт, предполагает представление их значений посредством лексикографических источников. Результатом комплексного описания является построение модели концепта, а именно определение его содержания [20].

Наряду с концептуальным анализом существует метод компонентного анализа, который может быть полезен для выделения тончайших различий между языковыми значениями и объяснения причин такого расхождения. Сравнительный метод предусматривает исследование и описание языка через его системное сравнение с другим языком с целью прояснения его специфичности. Он, в первую очередь, направлен на выявление различий между сравниваемыми языками, в связи с чем также называется контрастным [11].

Еще один метод лингвистического анализа - контекстуальный анализ. Его суть заключается в изучении окружения, в котором реализуется значение исследуемой языковой единицы. Различают макро- и микроконтекст. Макроконтекст предполагает существование окружения, позволяющего установить функцию единицы в тексте. Тогда как микроконтекст - минимальное окружение этой единицы.

Большинством учёных принято мнение, что невозможно чётко ограничить языковые средства оценивания. Это связано с тем, что оценка выражается в языке разными способами и на всех уровнях: оценочное значение может быть как закреплено во внутрисловных элементах, так и в целом высказывании, микротексте [4].

Таким образом, оценочный фрагмент в «языковой картине мира» отличается богатой палитрой разноуровневых средств выражения, как в немецком, так и в английском языках. К ним относят следующие:

- интонационные;

- графические;

- словообразовательные;

- лексические;

- синтаксические средства.

Соответственно, лингвокультурология является самостоятельным направлением лингвистики, поэтому в рамках этой дисциплины можно говорить о сформированной системе базовых терминов.

\section{ЛИТЕРАТУРА}

1. Арутюнова Н.Д. Аномалии и язык (к проблеме языковой «картины мира») // ВЯ - 1987. - № 3. - С.46.

2. Аскольдов С.А. Концепт и слово. // Русская словесность. От теории словесности к структуре текста. Антология. М., 1997. - С.267.

3. Вежбицкая А. Язык. Культура. Познание. М.: Русские словари, 1996. - С. 50.

4. Вольф Е.М. Функциональная семантика оценки. М.: Наука, 1985. - С. 45. 
5. Воркачев С. Счастье как лингвокультурный концепт. М, издательство 2004. - С. 66.

6. Карасик В.И., Слышкин Е.Е. Базовые характеристики лингвокультурных концептов // Антология концептов / Под ред. В.И. Карасика, И.А. Стернина. М.: Енозис, 2007 (а). - С. 87.

7. Красавский Н.А. Лингвистические методы исследования эмоциональной концептосферы//Лингвистические парадигмы: традиции и новации. - Волгоград, 2000. - С. 18.

8. Кубрякова Е.С. Об установках когнитивной науки и актуальных проблемах когнитивной лингвистики. / Вопросы когнитивной лингвистики. -2004, № 1. -С.6.

9. Кубрякова Е.С. Типы языковых значений: Семантика производного слова. М.: Наука, 1981. - С. 87.

10. Леонтович 0.А. Методы коммуникативных исследований. М.: Гнозис, 2011. - С. 79.

11. Лингвистический Энциклопедический словарь // Лингвистический Энциклопедический словарь / Главный редактор В.Н Ярцева. М.: Советская Энциклопедия, 1990. С. 559.

12. Маслова В.А. Когнитивная лингвистика: Учебное пособие / В. А. Маслова. - Мн.: ТетраСистемс, 2004. - С. 66.

13. Пименова М.В. Типология структурных элементов концептов внутреннего мира (на примере эмоциональных концептов). / Вопросы когнитивной лингвистики. -2004. -№ 1, с.83-90

14. Пищальникова В.А. История и теория психолингвистики: курс лекций/В.А. Пищальникова; Ин-т языкознания РАН, Московский гос. лингвистический ун-т.-М.:2005-С. 70.

15. Попова 3.Д., Стернин И.А. Когнитивная лингвистика. - М.: АСТ: Восток-Запад, 2007. - С. 145.

16. Скребцова Т.Г. Когнитивная лингвистика: Курс лекций. — СПб.: Филологический факультет СПбГУ, 2011. - С. 123.

17. Слышкин Г.Г. Прецедентный текст: структура концепта и способы апелляции к нему // Проблемы речевой коммуникации: Межвуз. сб. научн. тр. Саратов: Изд-во Сарат. ун-та, 2000. С. 15.

18. Слышкин Г.Г. Лингвокультурные концепты и метаконцепты: дис. ... д-ра филол. наук: 10.02.19. Волгоград, 2004. - С. 13.

19. Степанов Ю.С. Константы. Словарь русской культуры. М., 1997. - С. 134.

20. Стернин И.А. Коммуникативное и когнитивное сознание // С любовью к языку. Воронеж: Воронежский гос. ун-т, 2002. С. 44

( Л Литвяк Олеся Валерьевна (ole.litviak@yandex.ru), Смирнова Елизавета Ярославовна (liza-meshh@yandex.ru).

Журнал «Современная наука: актуальные проблемы теории и практики»

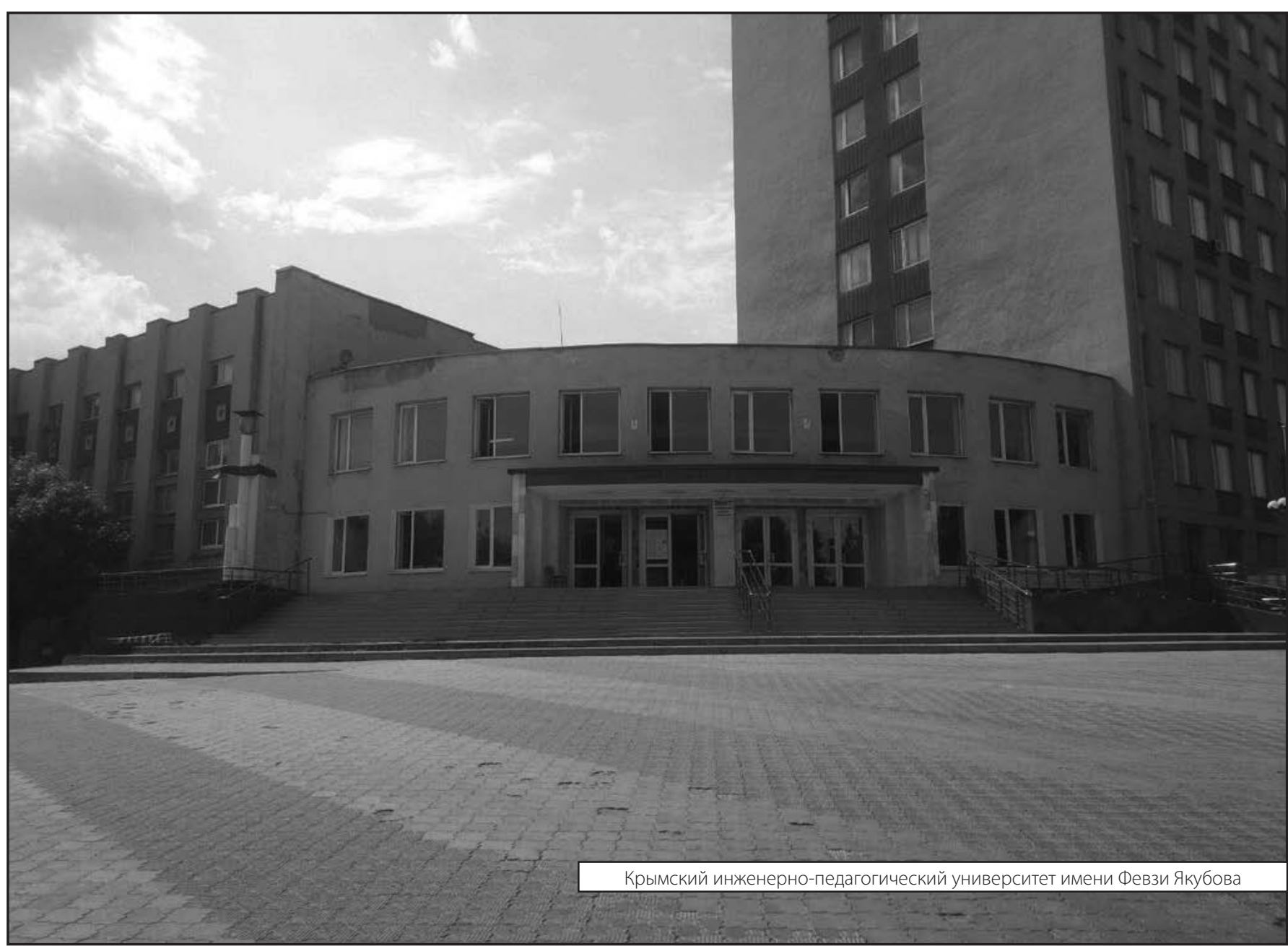

